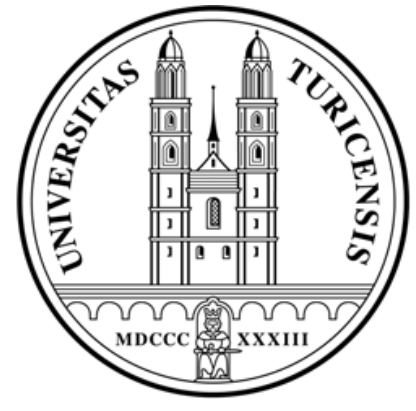

Institute for Empirical Research in Economics

University of Zurich

Working Paper Series

ISSN 1424-0459

Working Paper No. 378

Cooperativeness and Impatience in the Tragedy of the Commons

Ernst Fehr and Andreas Leibbrandt

July 2008 


\title{
Cooperativeness and Impatience in the Tragedy of the Commons
}

\author{
By ERNST FEHR AND ANDREAS LEIBBRANDT*
}

23 July 2008

\begin{abstract}
This paper examines the role of other-regarding and time preferences for cooperation in the field. We study the preferences of fishermen whose main, and often only, source of income stems from using a common pool resource (CPR). The exploitation of a CPR involves a negative interpersonal and inter-temporal externality because individuals who exploit the CPR reduce the current and the future yield for both others and themselves. Accordingly, economic theory predicts that more cooperative and more patient individuals should be less likely to exploit the CPR. Our data supports this prediction because fishermen who exhibit a higher propensity for cooperation in a laboratory public goods experiment, and those who show more patience in a laboratory time preference experiment, exploit the fishing grounds less in their daily lives. Moreover, because the laboratory public goods game exhibits no inter-temporal spillovers, measured time preferences should not predict cooperative behavior in the laboratory. This prediction is also borne out by our data. Thus, laboratory preference measures are useful to capture important dimensions of field behavior.
\end{abstract}

Keywords: cooperation, common pool resource, experiments, generalizability, methodology

JEL Classifications: B 4, C 9, D 8, O1

\footnotetext{
* Institute for Empirical Research in Economics, University of Zurich, Bluemlisalpstr. 10, CH-8006 Zurich (email: efehr@iew.uzh.ch; leibbrandt@iew.uzh.ch). We would like to thank Carina Cavalcanti for excellent assistance in the field and Björn Bartling, Uri Gneezy, Raul Lopéz-Péréz, Michel Maréchal, Frans van Winden and the conference participants at the ENABLE meeting in Mannheim for helpful comments. Financial support by the EU Research Network ENABLE (MRTN-CT-2003-505223) is gratefully acknowledged.
} 
Economic theory suggests that there is little cooperation for sustaining common pool resources (CPR) where individual and collective interests are in conflict. The standard assumption of pure self-interest implies that natural resources like fishing grounds or rain forests are overexploited, and that we are often trapped in an inevitable process that ends in the "Tragedy of the Commons" (Hardin, 1968). An additional aggravating factor for resource conservation is the propensity to discount future outcomes. The more impatient resource users are, the more they exploit natural resources. ${ }^{2}$ Interestingly, observations from the laboratory draw a more optimistic picture for the occurrence of cooperation in social dilemmas. Considerable evidence now shows that some individuals cooperate voluntarily to sustain CPRs or public goods (Ledyard, 1995; Fehr and Gächter, 2000; Camerer, 2003; Croson, 2008), especially if other individuals cooperate as well (Fischbacher et al., 2001; Frey and Meier, 2004; Shang and Croson, 2008), suggesting that some individuals have other-regarding preferences (Andreoni, 1990; Rabin, 1993; Fehr and Schmidt, 1999; Bolton and Ockenfels, 2000; Charness and Rabin, 2002; Dufwenberg and Kirchsteiger, 2004; Sobel, 2005; Falk and Fischbacher, 2006). There is also laboratory evidence that individuals differ with regard to their degree of impatience (Benzion et al., 1989; Ashraf et al. 2006).

In view of the key role that economic theory assigns to individuals' preferences in the exploitation of common natural resources, we study the impact of other-regarding preferences and time preferences on fishermen's propensity to exploit a CPR that constitutes their main, and often only, source of income. This is a nontrivial task because it requires independent measures of individuals' preferences. The problem is that field measures of preferences are often confounded by all sorts of factors - such as budget constraints, reputational incentives or information constraints - while for laboratory measures of other-regarding and time preferences it cannot be taken for granted that they predict people's behavior outside the laboratory (Karlan, 2005; Levitt and List, 2007). However, if it can be shown that laboratory measures of other-regarding and time preferences are significant predictors of fishermen's behavior in the field we can catch several flies at once. First, we provide evidence corroborating economic theories that predict the relevance of individuals' preferences for the exploitation of CPRs. Second, we provide evidence for the relevance of other-regarding behavior in a field setting that is of crucial economic importance for the people involved. And third, the study shows the relevance of suitably designed laboratory experiments for predicting field behavior.

\footnotetext{
${ }^{2}$ Farzin (1984) shows that this statement holds as long as capital requirements for exploiting natural resources are low. If capital requirements are high, however, impatient individuals might shy away from investing in technology that facilitates the exploitation of natural resources and, thus, exploit natural resources less. In our setting, capital requirements are relatively low.
} 
We achieve these goals with the help of a unique data set that combines individual laboratory and field behavior of fishermen. Our study takes place in Brazil and involves fishermen who live off fish and shrimp caught from a lake. As there is free access to the lake they face a CPR dilemma in their daily lives. There is suggestive evidence that fishermen in this setting differ in their level of cooperation to sustain fishing grounds, i.e. they seem to differ in the proportion of the catch that consists of small fish/shrimp which have not yet reached fertility (Cavalcanti, 2003). We have measures of both how strongly these fishermen exploit the fishing grounds in their daily lives as well as their decisions in two laboratory experiments: a public goods experiment where free-riding is the dominant strategy, and a time preference experiment. If laboratory preference measures capture relevant aspects of preferences in the field, economic theories of other-regarding preferences predict that individuals who exhibit a higher propensity to cooperate in the laboratory public goods experiment (i.e. demonstrate other-regarding preferences), and those who show more patience in the time preference experiment should exploit the CPR less for the following reasons: (i) a higher current exploitation reduces the current yield of other fishermen. Thus, ceteris paribus, other-regarding fishermen will impose fewer current negative externalities on others. (ii) a higher current exploitation (in terms of small fish/shrimp that have not yet reached fertility) also reduces the future yield for both others and themselves. Therefore, more other-regarding and more patient individuals will impose fewer future negative externalities on others and themselves.

Our data supports these predictions and shows that individuals' other-regarding and time preferences are important predictors of individual behavior in real world CPRs. Fishermen who are more cooperative in a public goods experiment exploit the fishing grounds less. They use fishnets with larger mesh sizes in which only bigger fish are caught, catch a smaller fraction of small shrimp, and also achieve a better price for one liter of their shrimp catch which is an alternative indicator for shrimp size. Impatient fishermen exploit the fishing grounds more heavily. They use fishnets with smaller mesh sizes, catch a higher fraction of small shrimp, and achieve a lower price per liter of their shrimp catch. Note that the behavior in the two laboratory experiments is predicted to be independent because in the public goods experiment time preferences can play no role. We find indeed that fishermen who are impatient in the time preference experiment are neither more nor less likely to cooperate in the public goods experiment. Therefore, our study reveals that laboratory measures of both other-regarding and time preferences independently influence cooperation in the field. In addition, we also find that conditional cooperation occurs in the laboratory and in the field 
setting. Fishermen are more likely to cooperate if they believe that other fishermen cooperate as well.

Most empirical studies of real world CPRs rely exclusively on field observations where deeper inferences about the relevance of individual preferences for field behavior are limited. For example, finding different levels of cooperation in field settings to sustain CPRs (Feeny et al., 1990; Sneath, 1998; Ostrom, 1999; Ostrom and Nagendra, 2006) can be often reconciled with self-interested behavior assuming the presence of reputation effects (Kandori, 1991), budget constraints (resource users may simply not have the financial means to buy expensive machinery that facilitates the exploitation of $\mathrm{CPR}$ ), other-regarding or time preferences, or any combination of these factors.

There are only a few studies that combine laboratory experiments with field observations for better understanding of field behavior (Karlan, 2005; Carpenter and Seki, 2005; Ashraf et al. 2006; Benz and Meier, forthcoming; List, 2006; Meier and Sprenger, 2007). Karlan (2005) conducted economic experiments with borrowers in a Peruvian microcredit program and reports that the behavior in a trust game predicts loan repayment. Individuals who transfer more money back to their trustor in a trust game are also more likely to repay their loans. This study shows nicely that behavior in laboratory experiments can predict field behavior, but it fails to clarify the role of other-regarding preferences in the field. In this trust game, trustors knew their trustees personally, and hence any back-transfer can be reconciled with selfishness in the presence of reputation effects. ${ }^{3}$ List's (2006) study with sports card traders suggests that cooperativeness may be less pronounced in the field compared to the laboratory. He finds that dealers who are classified as "local dealers" show gift exchange behavior in the laboratory and the field while dealers who are classified as "nonlocal dealers" show less overall cooperation in the field. This finding is consistent with a role for strategic reputation building among local dealers but it is also possible that local dealers care, per se, for their reputation. Our study differs from List's in that we have both laboratory and field measures from the same individuals which enable us to directly study the extent to which the laboratory preference measures predict an individual's field behavior.

The study by Carpenter and Seki (2005) suggests that cooperative fishermen - as measured by a laboratory public goods game - are more prevalent in groups which

\footnotetext{
${ }^{3}$ A similar argument also applies to the public goods game in Karlan (2005) which was not played anonymously. In addition, it was a step level public good with many Nash equilibria, i.e., even purely selfish players have an incentive to contribute if they believe to be the pivotal players. The experiment thus cannot be used to measure other-regarding preferences.
} 
implemented team-based compensation and work schemes. Cooperative fishermen are more likely to work in groups of fishing boats where income and operating expenses are shared than in those groups of boats where sharing only occurs among the members of the own boat. In contrast to our study, the authors do not examine individual cooperation behavior in the field, but only aggregate productivity across the two different groups.

Our findings indicate that there is no insurmountable gap between the laboratory and the field. If laboratory preference measures are significant predictors of field behavior, and if the predictions confirm the hypotheses of economic models that assume stable preferences, then there is sufficient continuity between the laboratory and the field to render lab experiments informative for field behavior. In addition, our evidence that other-regarding preferences and time preferences are important for the exploitation of CPRs suggests ways in which the overexploitation of CPRs may be reduced. Economic policies, for example, which shift the perception of the costs of current overexploitation into the present are likely to constrain overexploitation. Likewise, belief management and information policies which take into account the inherent bandwagon effects caused by preferences for conditional cooperation may be used for the management for CPRs.

The paper proceeds as follows. Section I presents the field setting and the field data. Section II presents the two laboratory experiments. Section III links the behavior in the laboratory experiments with the field data. Section IV concludes.

\section{Field Setting and the Data}

\section{A. Field Setting}

Our study took place at a lake in northeastern Brazil. Several rural fishing villages ${ }^{4}$ are situated around this lake where fishing is the main and often the only possible profession. Most fishermen catch fish and shrimp on their own, sell their catch at fish markets and thus provide their family with nutrition and income. There is free access to the fishing grounds (fish and shrimp), and a fisherman's capital requirements are rather low. For example, the costs for a fishnet can be normally amortized with the income generated from one week's

\footnotetext{
${ }^{4}$ We use the term "villages" for reasons of simplicity. In this field setting, these are sometimes not villages in the ordinary sense, but rather community agglomerations where the borders between the neighboring community agglomerations or villages are unclear.
} 
catch. ${ }^{5}$ While fishing, fishermen are typically scattered in the lake and fish at their preferred, sometimes remote $\operatorname{spot}(\mathrm{s})$. Other fishermen usually respect these spots, i.e. most fishermen do not fish at or close to another fisherman's spot. Their respect for others' fishing spots means that the fishing ground at this lake is not a pure CPR, but shares some features of a private property. The fishermen are of course aware of the fact that overfishing has negative externalities on others but the private aspects of their fishing spots also means that private investments like the refraining from catching small shrimp/fish affects their own chance to catch these same shrimp/fish at a larger size in the future at the same spot.

There are no legal constraints concerning the mesh size of the fishnet and no legal regulations concerning the catching of shrimp. There is just one legal regulation concerning the catching of fish which is the prohibition of catching small fish (below 20-30 centimeters, depending on fish type). This regulation is, however, not enforced. Most fishermen do not fear controls or social pressure; small fish are frequently offered at markets and in restaurants. In recent years, many fishermen have complained about decreasing catch rates and report finding fewer big fish, which they mostly blame on the overexploitation of the fish resources, that is, the catching of large amounts of small and infertile fish (Cavalcanti, 2003). In order to generate an alternative income, many fishermen started to catch shrimp. Apparently, the shrimp population is diminishing too. A research project with fishermen revealed their strong concern about the excessive exploitation of the shrimp resources (Cavalcanti et al., 2008). Governmental and local university institutions have taken note of the severity of the situation and first steps were initiated to help sustain the fishing grounds. A management council was introduced to examine and alleviate the current fishing situation.

\section{B. Field Data}

We gathered overall data from 208 fishermen who took part in a survey and a public goods and a time preference experiment in September 2006. In addition, we visited a sub-sample of these fishermen in April 2008 to observe the mesh size of their fishnets.

During the survey and the experiment, participants received a code to ensure anonymity and were free to leave at any point of time. We told the fishermen that the purpose of the survey is the better understanding of their current situation. Each fisherman was

\footnotetext{
${ }^{5}$ Note that fishnets differ according to their mesh size. However, the price of the fishnet is independent of the mesh size. Fishnets with smaller mesh sizes are not cheaper/more expensive than fishnets with bigger mesh sizes. The capital requirements for catching shrimp are even lower and close to zero, since fishermen build their shrimp traps from used PET bottles.
} 
individually interviewed by biologists or biology students who were familiar with the situation of the fishermen in this area. The survey lasted between 15-30 minutes and included several different pre-tested fishing questions that were placed in a large set of non-fishing related questions.

Most fishermen are male $(\mathrm{N}=179)$ and catch both fish and shrimp $(\mathrm{N}=131) .43$ fishermen catch only fish and 34 only shrimp. The majority of our participants are experienced and full-time fishermen (average years in profession: 19.2 years, average weekly work time: 40.2 hours) who generate their income almost exclusively from fishing (average monthly income 360 Reais $^{6}$ ). Fishermen spent on average 3.9 years in school and had approximately three children. About three-fourths of the fishermen who catch fish use a fishnet as fishing instrument.

We investigate the cooperation behavior of fishermen in sustaining fishing grounds with three variables (mesh size, small shrimp, and shrimp price) to provide a robustness check of our results and because each measure has different advantages. All three measures are proxies for CPR exploitation because they provide information about the proportion of small fish/shrimp caught.

The first variable mesh size is a very precise, albeit indirect estimate of the minimum fish size fishermen catch. The smaller the mesh size of the fishnet, the more small fish are caught in the fishnet. ${ }^{7}$ As a rough reference point, small fish that are below the legal minimum size (20-30 centimeters depending on fish type) are frequently caught in fishnets with mesh sizes that are smaller than five centimeters. The data of the mesh sizes of the fishnets comes from two sources: survey responses in 2006 and field observations in 2008. While re-visiting the fishermen in 2008, we investigated the fishnets of approximately every third fisherman who participated in 2006 and used a fishnet (35 out of 121). ${ }^{8}$ We find that the two year old survey responses are very much in line with the recent field data (Spearman

\footnotetext{
${ }^{6}$ The Brazilian currency is called Real (singular) or Reais (plural). 1 Real equaled US $\$ 0.47,360$ Reais $=$ US $\$$ 170 .

${ }^{7}$ In case fishermen possessed more than one fishnet, the variable mesh size specifies the mesh size of the fishnet that is used most frequently. Using a fishnet with a larger mesh size can lead to an income reduction of approximately eight percent. We asked some fishermen to fill out a daily report for several weeks where they reported which mesh size they used, the amount of fish they caught, and the weight in kilograms of fish they caught. Nine fishermen reported frequently using two different mesh sizes. When they use the smaller mesh size, they report catching a 21.5 percent larger number of fish per hour $(p<0.01)$ and 16 percent more kilograms of fish per hour $(\mathrm{p}=0.07)$. If we assume that the additional fish caught with a small mesh size are all small fish that are sold at a 50 percent lower price (i.e., instead of a normalized price of 1 for larger fish the small fish are sold at a price of 0.5$)$, the fisherman who use a small mesh size earn roughly 8 percent $(0.16 \times 0.5)$ more income per hour. A 50 percent lower price for small fish is a realistic assumption.

${ }^{8}$ Typically, we went to their houses or to the lake and asked them to show us their fishnet.
} 
Rang Correlation, $\mathrm{r}=0.70 ; \mathrm{p}<0.0001)$. Almost two-thirds (21) use the same mesh size they reported in the survey, nine use a larger mesh size and only five use a smaller mesh size. In the cases where fishermen used a different mesh size two years later, they claimed that the old fishnet was either damaged or stolen. Figure 1 shows which mesh size the fishermen use in our sample. ${ }^{9}$ Almost two-thirds of the fishermen use a mesh size that is smaller than five centimeters, with a mean of 4.43 centimeters. The most frequently used mesh sizes are 3.5 (28.9 percent), 5 (15.7 percent), and 6 (17.4 percent) centimeters which also corresponds with the statements of a regional fishnet manufacturer who mainly sells these three mesh sizes.

The second variable small shrimp specifies the fraction of shrimp caught measuring less than two centimeters, which is a very low threshold taking into consideration that this type of shrimp reaches fertility at a length of three to four centimeters. ${ }^{10}$ During the survey, we showed the fishermen a shrimp measuring two centimeters and asked them whether they catch such small shrimp and, if yes, whether the fraction of these small shrimp in their catch is very small, small, medium, or high. Therefore, the variable small shrimp is a direct ordinal estimate with five different categories about the fishermen's catch composition of shrimp. Figure 2 illustrates that almost half of our participants catch a high fraction whereas around 40 percent catch a small or very small fraction of small shrimp. Only three percent report not catching small shrimp.

The third variable shrimp price specifies the price fishermen achieve per liter shrimp. It also gives us an idea about the average catch size because the selling price depends on the size, and one liter of small shrimp is sold more cheaply on the market than one liter of big shrimp. Since shrimp prices depend also on other variables like regional demand and supply, this measure is not only an indirect but also quite noisy estimate of the shrimp size. ${ }^{11}$ Figure 3 shows that there are big differences. About 20 percent of the fishermen report receiving less than 0.5 Reais whereas almost 50 percent report to receive at least one Real per liter shrimp.

\footnotetext{
${ }^{9}$ In the following, we used the updated data on the mesh size (in case there are differences between the older survey responses and the recent field observations, we used the latter). All results are, however, very similar if we exclusively use the older data.

${ }^{10}$ For catching shrimp, the large majority of the fishermen use modified PET bottles with many small holes. Most fishermen use hundreds of these bottles and the size of the holes often varies slightly. Even very small differences in the size of the holes make a great difference as to which shrimp get caught. Since it is very difficult to capture these differences, we did not ask fishermen about the average size of the holes in their PET bottles, but asked them directly what fraction of their caught shrimp is small. In contrast, we did not ask the fishermen what fraction of their caught fish is small because of the existence of a legal minimum catch size. We did not want to make fishermen state doing something illegally.

${ }^{11}$ This is even more the case for the price fishermen achieve for one kilogram of their fish catch. In contrast to shrimp, fish prices also depend on the exact type of fish. For some fish types, fishermen achieve a comparatively high price even if the fish is small. Therefore, we do not report fish prices as proxies for the fish size.
} 
It turns out that our three exploitation measures of CPR are significantly correlated, consistent with the view that they all measure a similar construct. Fishermen who use larger mesh sizes of the fishnet catch a lower fraction of small shrimp (Spearman Rang Correlation, $\mathrm{r}=-0.39, \mathrm{p}<0.001)$ and sell their shrimp catch more expensively $(\mathrm{r}=0.30, \mathrm{p}=0.003)$. Moreover, fishermen who catch a higher fraction of small shrimp sell one liter of their catch more cheaply $(\mathrm{r}=-0.34, \mathrm{p}<0.001)$.
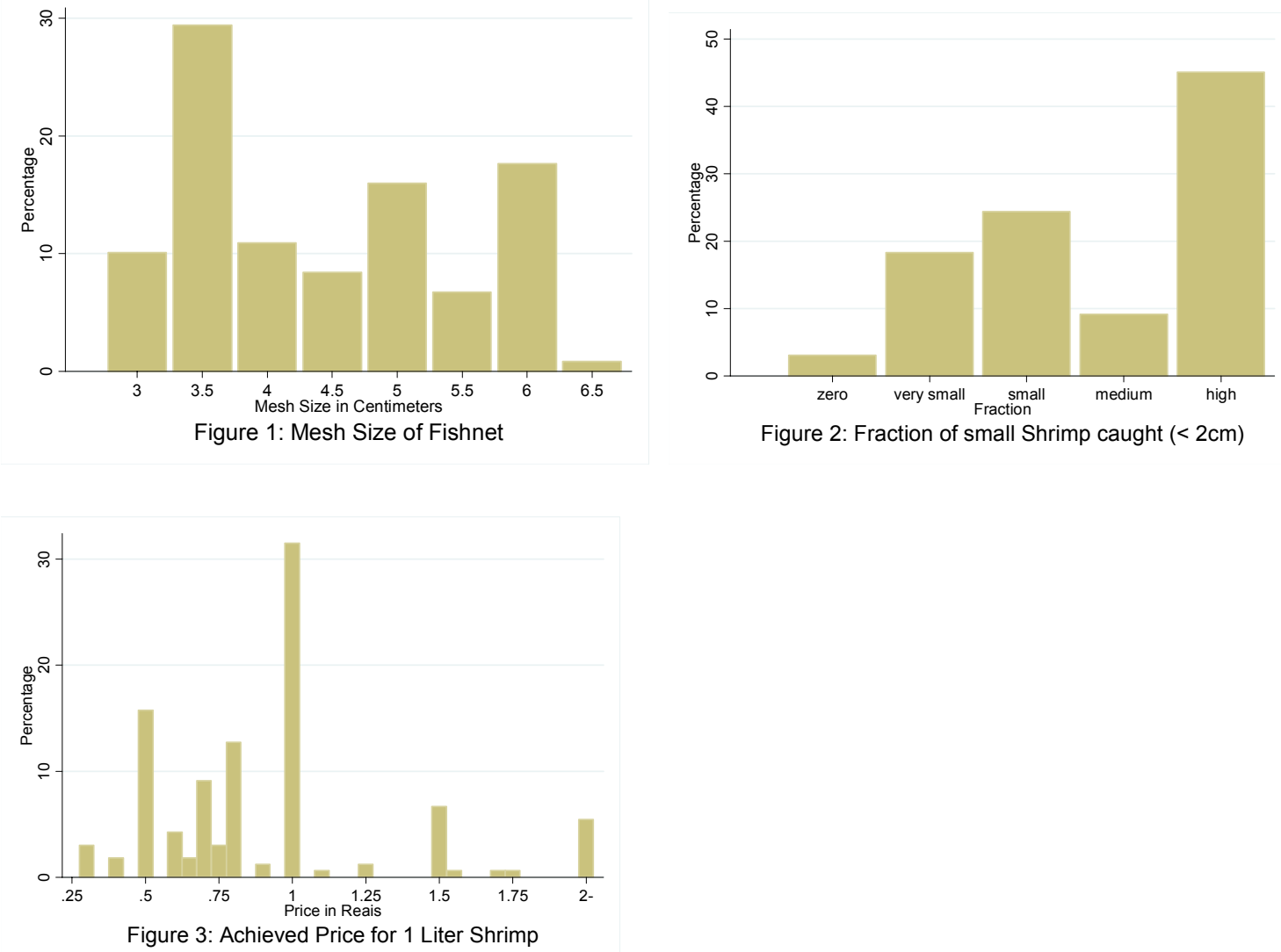

\section{The Laboratory Experiments}

\section{A. The Public Goods Experiment (PGE)}

All fishermen participated in an anonymously played public goods experiment with comparatively high monetary stakes; participants earned on average 1.37 times their available daily income. They were divided in groups of four and played this experiment for five periods in the same group. The payoff function in each period was: $\prod_{i}\left(x_{i}, x_{j}\right)=6.5+0.5 \times\left(\sum_{j \neq i} x_{j}-x_{i}\right)$. At the beginning of each period, each fisherman had to 
decide how many out of seven monetary units (MUs) he contributes $\left(x_{i} \in\{0,7\}\right)$ to the public good. ${ }^{12}$ For each unit he contributed, he increased the monetary payoff of each of his group members $j$ by 0.5 MUs, but at the same time, his own balance was reduced by 0.5 MUs. For each unit one of his group members decided to contribute, his own balance was increased by 0.5 MUs.

Since the fishermen's net return from contributing was negative, never contributing was always in their material interest if the selfishness and rationality of all individuals was common knowledge. However, if all four individuals in the group decided not to contribute, each of them only earned 6.5 MUs $(6.5-0+0)$ compared to 13.5 MUs $(6.5+0.5 \times 7 \times 3-$ $0.5 \times 7)$ if all of them contributed all seven units. The procedure was the same in all periods: first fishermen simultaneously made their choice, then indicated their expectations for the contributions of the other group members, and then received information about how many units each of their group members contributed. All rules were explained twice to the fishermen, first in group and then afterwards individually before the first decision was made. No fisherman was informed about the identity of his group members. The game lasted approximately two and a half hours.

\section{B. Results PGE}

We can reject the standard prediction that all fishermen do not contribute in the PGE. 87.02 percent contributed in the first period. Most fishermen chose to contribute five out of seven possible units (18.27 percent), and almost half of the fishermen contributed between three and five units. In the remaining four periods, contributions declined constantly. Subjects contributed significantly less in the last compared to the first period (average contributions: 3.37 vs. 4.03; T-test, $\mathrm{t}=3.850, \mathrm{p}<0.001$ ), and the fraction of fishermen who did not contribute more than doubled (30.77 percent versus 12.98 percent).

We find that the expectations about the average contributions in the own group is by far the most important explanatory variable in an OLS regression, with contributions in the first period ${ }^{13}$ as dependent variable, $(\mathrm{t}=6.46, \mathrm{p}<0.001)$. This confirms earlier evidence that many individuals cooperate voluntarily, but only if they hold the belief that other individuals

\footnotetext{
${ }^{12}$ Three MUs always equaled one Real.

${ }^{13}$ We also used individuals' average contribution over all five periods as a dependent variable in an OLS regression. We find that average expectations about all group members contributions is the most important explanatory variable $(\mathrm{p}<0.001)$ and that older fishermen tend to contribute more on average (significant on 90 percent level).
} 
also cooperate, i.e., they are "conditional cooperators". Moreover, we observe that the years of being a fisherman and the village size are negatively related to the contributions in the first period (significant at 95 percent level). We control for these variables in all of our following regressions.

\section{The Time Preference Experiment (TPE)}

We used a simple and fast time preference experiment to obtain a measure for impatience. In our TPE, all fishermen had to indicate whether they prefer one unit of a good immediately or two units of the same good the next day. If they preferred the good immediately, the fishermen received the good immediately after the experiment. If they preferred two units of the good the next day, we distributed vouchers with which they could collect their good the next day a village leader's house. The village leader was elected by the residents and is usually considered an extraordinarily trustworthy person. We selected two different goods to capture impatience: mineral water and money. Each fisherman indicated his time preference for both goods. The goods were presented in random order and one was randomly picked for payment. The stakes for money and mineral water were about the same and relatively high ( 0.32 of the daily income for the patient, i.e. deferred choice).

We chose mineral water because it often measures immediate utility since individuals tend to consume it the moment they get it. This is not necessarily the case for money. In our setting in particular, most fishermen will not be able to spend money immediately. This is because the study area is remote and there are very few possibilities for spending money in the immediate vicinity. Another favorable attribute of mineral water is that it clearly has an arousing feature (to satisfy thirst), while this is less clear with money. Evidence indicates that time preference experiments only predict future outcomes if the rewards are presented in such a way that the focus is on their arousing features (Mischel et al., 1989). Money, on the other hand, is the standard good for measuring time preferences and there is already some evidence that decision tasks with money capture time preferences for behavior like saving quite accurately (Frederick et al., 2002). Still, we suspected that for our setting, a decision task with mineral water may be better suited to capture the impatience of fishermen in the field.

\section{Results TPE}

Almost half of our participants preferred both goods immediately (45.67 percent) and only one third (33.17 percent) was more patient and preferred both goods the next day. 21.15 percent preferred one good today and the other the next day. We observe that the two 
decisions are significantly correlated $(\mathrm{r}=0.58, \mathrm{p}<0.001)$, and that fishermen were somewhat more impatient with regard to mineral water than with money $\left(\kappa^{2}=1.65, p<0.20\right) .59 .6$ percent preferred mineral water immediately compared to 52.8 percent who preferred money immediately.

In a probit model with an impatience dummy for mineral water as the dependent variable, we find none of the control variables ${ }^{14}$ significant; for instance, income has no predictive power $(\mathrm{t}=0.68, \mathrm{p}=0.495)$. In a probit model with an impatience dummy for money as the dependent variable, we find that only age has a significant impact. Older fishermen are slightly more patient with regard to money $(\mathrm{t}=1.71, \mathrm{p}=0.087)$.

\section{E. The Relation between Other-regarding Preferences and Impatience in the Laboratory}

Other-regarding and time preferences might play an important role in explaining the individual degree of CPR exploitation in the field. The laboratory provides an opportunity for deriving distinct measures for both factors. We use our PGE to obtain an individual measure for other-regarding preferences and the TPE to obtain an individual measure for impatience. Because there are no inter-temporal spillovers in the PGE, measured time preferences in the TPE should not predict other-regarding preferences in the laboratory, a prediction our data supports. Individuals who are impatient in the TPE are not more or less likely to contribute in the PGE. Table 1 shows that the impact of our time preference measures on cooperation behavior in the laboratory is close to zero and insignificant. In the first two columns, we use the time preferences with regard to mineral water as the independent variable. We see that they have no predictive power for the behavior in the PGE regardless of whether we use controls. The coefficients are close to zero and far away from any level of significance $(p>$ 0.730). In the last two columns, we use the time preferences with regard to money as the independent variable. Again, the time preference measure is uninformative in a model with and without controls. Thus, our two laboratory experiments provide us with independent measures for other-regarding and time preferences that we will later use as distinct explanatory variables for how strongly fishermen exploit fishing grounds.

\section{[INSERT TABLE 1 ABOUT HERE]}

\footnotetext{
${ }^{14}$ We use the same controls as in table 1 (age, gender, family size, schooling, religiosity, years in profession, session size, village size, income, and weekly hours fishing).
} 


\section{Predicting Cooperation in the Field in sustaining CPR with Laboratory Measures}

The heart of this paper uses the laboratory measures of other-regarding and time preferences to predict the individual level of CPR exploitation. Our measures of CPR exploitation capture how strongly individuals exploit fishing grounds. We study the exploitation of fishing grounds using the variables mesh size, small shrimp, and shrimp price. We hypothesize that fishermen who contribute more in the PGE tend to exploit the fishing grounds less, and that fishermen who are impatient in the TPE tend to exploit the fishing grounds more.

\section{A. Other-regarding Preferences, Impatience and Mesh Size of Fishnet}

In this section we link the behavior in the PGE and the TPE to the used mesh size of the fishnet. We hypothesized that fishermen who contribute more in the PGE use larger mesh sizes and that impatient fishermen use smaller mesh sizes. Figure 4 illustrates that there is indeed a positive relationship between contributions in the first period of the PGE and the mesh size. For instance, fishermen who contribute six or seven units in the first period of the PGE use on average a mesh size of 4.88 centimeters (mode: 6 centimeters) whereas fishermen who contribute nothing or just one unit use a one centimeter smaller mesh size (3.88 centimeters, mode: 3,5 centimeters). This difference is significant at any conventional level (T-test, $\mathrm{t}=-3.803, \mathrm{p}<0.001)$ and substantial. ${ }^{15}$

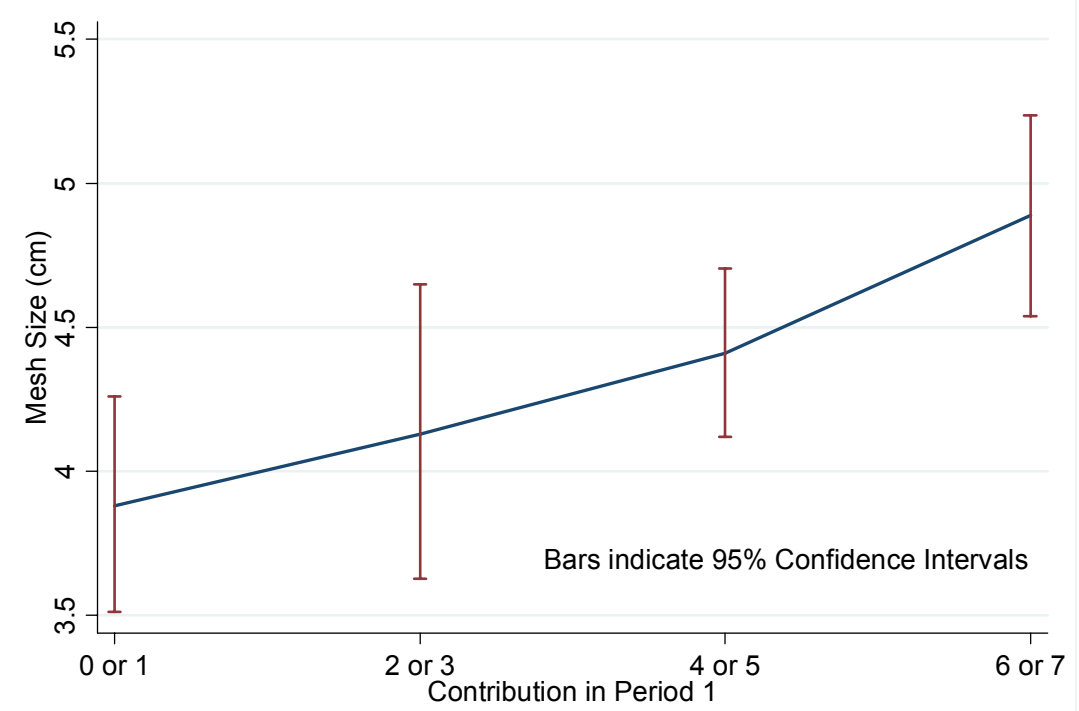

Figure 4: Contributions in PGE \& Mesh Size of Fishnet

\footnotetext{
${ }^{15}$ While it is difficult to find an exact correlation between a difference of one centimeter in mesh size with respect to the size of fish ultimately caught (since this does depend on the fish type), the fishermen estimate this to be approximately 3-7 centimeters. Note as a rough reference point that small fish that are below the legal minimum size $(20-30$ centimeters depending on fish type) are frequently caught in fishnets with mesh sizes that are smaller than five centimeters.
} 
In the first column of Table 2, we use an OLS model to predict the used mesh size. In this model we use as independent variables the behavior in our two laboratory experiments and several socio-economic and fishing related measures. We find that three variables are significant on the 99 percent level: contributions in the PGE, the time preference for mineral water, and harm perception ${ }^{16}$. As hypothesized, contributions in the PGE are positively related to the mesh size of the fishnet. For each additional unit a fisherman contributes in the first period of the PGE, he uses on average a 0.154 centimeter larger mesh size $(t=3.45, p=$ 0.001). We also obtain this result if we use different measures for other-regarding preferences in the PGE; for instance, if we replace contributions in the first period in this model with average contributions during all five periods, we find that an increase of one unit in average contributions leads to an increase of 0.121 centimeter in mesh size $(t=2.74, p=0.007)$.

\section{[INSERT TABLE 2 ABOUT HERE]}

Moreover, we can confirm our hypothesis that impatience is negatively related to mesh size. Fishermen who prefer the single amount of mineral water immediately in the TPE use on average a 0.568 centimeter smaller mesh size $(\mathrm{t}=2.89, \mathrm{p}=0.005)$. We do not obtain a similar result for the time preference with regard to money. The decision to opt for one unit of money immediately over two units the next day neither has predictive power for the mesh size in our model nor in a model where we do not control for the time preference with regard to mineral water $(\mathrm{t}=0.20, \mathrm{p}=0.843) .{ }^{17}$ This is a first indication for our conjecture that money is less suitable for capturing time preferences in our field setting.

The variable harm perception plays also an important role for the used mesh size. This variable indicates which mesh size fishermen perceive as harmful for the fish population. Fishermen who already perceive a relatively large mesh size as harmful tend to use larger mesh sizes $(t=3.05, p=0.003)$. In addition, we find that field beliefs matter. Our field belief variables measure how pessimistic/optimistic fishermen's beliefs are about other fishermen's fishing behavior, compared to the average belief in the same village. Concerning the mesh

\footnotetext{
${ }^{16}$ Harm perception indicates which behavior fishermen perceive as harmful for the fishing grounds. The variable is defined more closely below.

${ }^{17}$ If we do not control for time preferences with regard to money, the impatience dummy for mineral water is still highly significant $(\mathrm{t}=2.24, \mathrm{p}=0.028)$.
} 
size, we ask fishermen about their beliefs which mesh size other fishermen in their village use and compare it to the average belief of all participating fishermen in this village. For instance, a fisherman who believes that the mesh size typically used in his village is smaller than the average belief is assigned a negative value in the field belief variable (own belief - average belief in village $<0$ ), and we denote him here a pessimist for simplicity. It turns out, that the more pessimistic a fisherman is, the more likely he is to use a small mesh size $(\mathrm{t}=1.93, \mathrm{p}=$ $0.056)$.

\section{B. Other-regarding Preferences, Impatience and Shrimp Size}

In this section, we link the behavior in the PGE and the TPE with the frequency with which fishermen catch small shrimp. We hypothesized that fishermen who contribute more in the PGE are less likely to catch high fractions of small shrimp and that fishermen who are impatient in the TPE are more likely to catch high fractions of small shrimp. This is exactly what we observe. For instance, we find that only 41 out of 106 fishermen (38.7 percent) who contribute between four and seven units in the first period of the PGE catch a high fraction of small shrimp, in comparison to 33 out of 59 fishermen (55.9 percent) who contribute between zero and three units $\left(\kappa^{2}=3.89, \mathrm{p}<0.05\right)$. Our hypothesized effect is even more pronounced in a regression model with controls. In the second column of Table 2, we use an ordered probit model to predict the fraction of small shrimp caught below two centimeters. We observe that contributions in the PGE, the time preference with regard to mineral water, and field beliefs are significant predictors at the 99 percent level. The coefficients reported in this model represent the marginal effects. Thus, the probability of a fisherman catching a high fraction of small shrimp decreases by 5.6 percent, for instance, for each additional unit he contributes in the first period of the PGE. This means that a fisherman who contributes all seven MUs is 39.4 percent less likely to catch a high fraction of small shrimp compared to a fisherman who does not contribute $(\mathrm{t}=-2.71, \mathrm{p}=0.007)$. Average contributions in the PGE also predict the fraction of small shrimp caught. If we replace contributions in the first period with the average contribution in all five periods, an increase of one unit in average contribution is associated with a 4.5 percent decrease in probability of catching a high fraction of small $\operatorname{shrimp}(\mathrm{t}=-2.47, \mathrm{p}=0.013)$.

A further piece of evidence that impatience helps understand how strongly CPRs are exploited comes from the investigation of the relationship between the time preferences with regard to mineral water and the fraction of caught small shrimp. We can see in Figure 5 that fishermen who prefer mineral water immediately tend to catch a higher fraction of small 
shrimp. This becomes especially clear when looking at the right side of this figure. 55.88 percent (57 out of 102) of the fishermen who prefer the immediate single amount of mineral water catch a high fraction of small shrimp, in contrast to only 26.98 percent ( 17 out of 63) of the fishermen who prefer to have double the amount of mineral water the next day $\left(\kappa^{2}=\right.$ $12.00, \mathrm{p}<0.001)$.

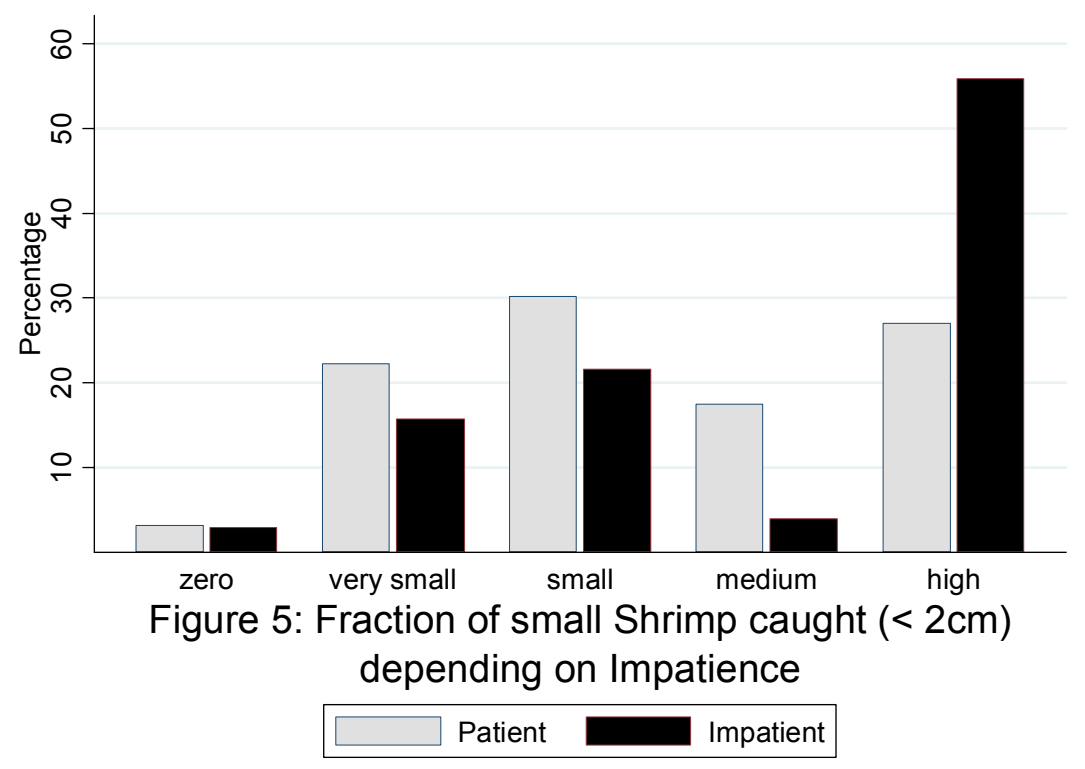

In the second column of Table 2, we observe that the impatience dummy for mineral water is also a significant predictor of the fraction of small shrimp caught in a regression with controls. Fishermen who are impatient in the TPE with regard to mineral water are 32.2 percent more likely to catch a high fraction of small shrimp $(t=-3.45, p=0.001)$. The time preference with regard to money does not help explain the fraction of small shrimp caught in this model $(t=0.44, p=0.660)$. However, if we exclude the impatience dummy for mineral water from this model, impatience with regard to money predicts the fraction of small shrimp caught correctly (but weaker than impatience with regard to mineral water; $\mathrm{t}=-1.96, \mathrm{p}=$ $0.050)$.

Furthermore, we find that field beliefs are important in predicting the fraction of small shrimp caught. Concerning the fraction of small shrimp caught, we ask fishermen about their beliefs what fraction of small shrimp the most prominent fisherman catches in their village and compare it to the average belief in this village. A fisherman gets a positive value if he believes that this fraction is higher compared to the average belief (own belief - average belief in village $>0$ ) and we denote him as a pessimist. It turns out that fishermen are more 
likely to catch a high fraction of small shrimp the more pessimistic they are $(\mathrm{t}=-5.12, \mathrm{p}<$ $0.001)$. In addition, we find that female fishermen ${ }^{18}$ and fishermen who use a larger number of shrimp traps catch a higher fraction of small shrimp (both significant at 95 percent level). This result suggests that that those who use a larger number of shrimp traps have a higher share of traps that catch also small shrimp.

\section{Other-regarding Preferences, Impatience and Shrimp Price}

We now turn to the investigation of the relationship between the behavior in the PGE and TPE and the price fishermen achieve for one liter of their shrimp catch on the fish market. We hypothesized that fishermen who are cooperative in the PGE tend to achieve higher prices and that impatient fishermen tend to achieve lower prices, since there is a positive correlation between prices and average catch size. Figure 6 gives a first impression how contributions in the PGE are related to the achieved price for shrimp. While we can see that the confidence intervals are relatively large (which is not surprising given that the price measure is indirect and noisy), we still find an effect. Fishermen who contribute more in the first period of the PGE tend to achieve higher prices when selling their shrimp. The difference is substantial: fishermen who contribute six or seven units sell their catch 50 percent more expensive than fishermen who contribute zero or one unit (1.02 Reais vs. 0.68 Reais; T-test, $\mathrm{t}=-2.93, \mathrm{p}=$ $0.004)$.

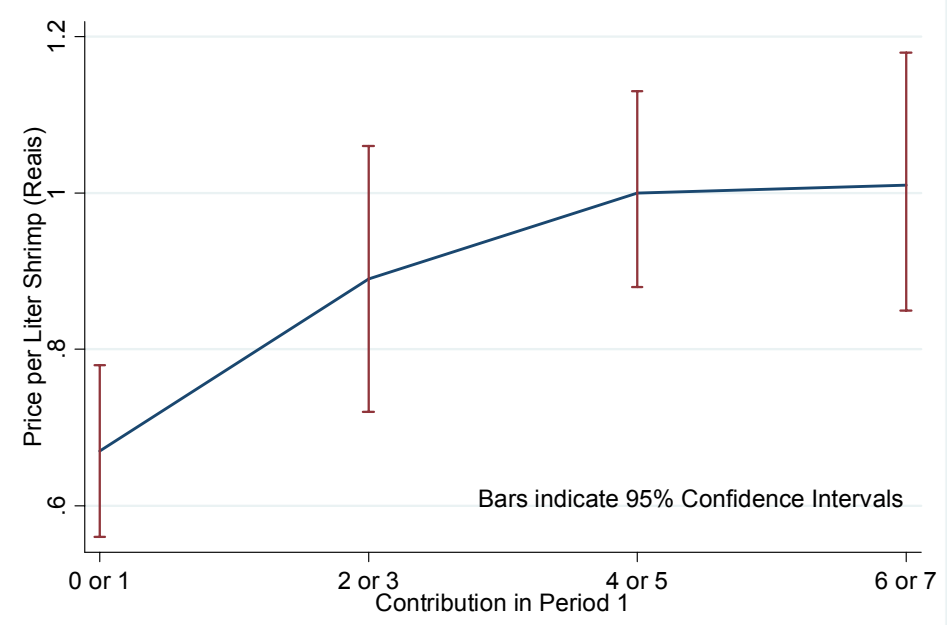

Figure 6: Contributions in PGE \& Price for Shrimp Catch

\footnotetext{
${ }^{18} 25$ out of 152 individuals are females in this regression.
} 
In the third column of Table 2, we use the variable shrimp price as the dependent variable in an OLS model. We observe that four variables are significant on the 90 percent level: contributions in the PGE, the impatience dummy for mineral water, the catch size, and the village size. Fishermen who contribute seven compared to zero units in the first period of the PGE, sell one liter of shrimp for 0.27 Reais $(7 \times 0.039)$ more on the market $(\mathrm{t}=1.92, \mathrm{p}=$ 0.057). Like in the other two models in column one and two, the time preference with regard to mineral water has a significant impact. Fishermen who prefer the single amount of mineral water immediately achieve 0.10 Reais less for one liter shrimp $(t=1.74, p=0.084)$. The impatience dummy for money has, in contrast, no predictive power. This is also not the case if we exclude the impatience dummy for mineral water from this model $(t=-0.19, p=0.853)$. Furthermore, we observe that fishermen who live in larger villages and fishermen who catch more shrimp achieve lower prices which may be explainable by a pressure on the prices where there is a high local supply of shrimp.

\section{Conclusion}

In this paper, we examine whether laboratory measures of other-regarding and time preferences predict individuals' degree of cooperation in a CPR context that is of crucial economic importance for the fishermen involved. We provide clear evidence that otherregarding preferences and time preferences are independent predictors of individuals fishing practises. Fishermen who contribute more in a public goods experiment exploit the fishing grounds less, and fishermen who are impatient with regard to mineral water in a time preference experiment exploit the fishing grounds more. The fact that our laboratory measure for other-regarding preferences predicts field behavior increases our confidence about the behavioral relevance of other-regarding preferences gained from laboratory experiments. Moreover, we show that the laboratory is useful in deriving distinct individual preference measures which affect cooperation in the field. If only field data were available, it would have remained unclear whether CPR exploitation stems from self-interest, impatience, or both. However, by combining laboratory experiments and field data, we could show that both are related to how strongly fishermen exploit the CPR. In addition, we observe that impatience in our field setting can be better predicted with a decision task with mineral water than with money. Therefore, we believe that it can be beneficial to break with the convention of exclusively using money to capture time preferences, but instead choosing the good which is best suited to capture immediate utility. 
Our results may have important implications for policymakers, managers, and social scientists. When designing policy measures it is useful to know that strong impatience may be an obstacle for the implementation of resource preserving policies. Likewise, it may be useful to know about the conditional nature of fishermen's other-regarding preferences, i.e., their conditional willingness to cooperate even if cooperation goes against their immediate selfinterest. Thaler and Benartzi (2004) designed the Smart commitment mechanism which helped impatient employees who lack self-control increase their future savings. We imagine a similar mechanism for promoting resource conservation which incorporates both the propensity to discount future outcomes as well as the propensity to cooperate voluntarily (if others cooperate as well). Individuals can be approached to commit in advance to change their behavior towards a more sustainable use of resources, but this commitment only becomes binding if a specified majority of the other resource users also commits. For example, the fishermen could commit (e.g., by signing a contract with an environmental agency) to exchange their fishnets with small mesh size to fishnets with bigger mesh size in the future if a specified majority of the other fishermen is also willing to commit to this policy. This proposal takes advantage of the conditional nature of fishermen's willingness to cooperate and, in addition, it reduces the perception of the cost of cooperation by shifting the exchange of the fishnets into the future. Thus, impatient individuals who lack self-control and conditionally cooperative individuals are more likely to commit to this policy than to an alternative policy that requires unconditional cooperation and imposes the cost of cooperation in the current period. Similar mechanisms can be applied to other settings as well. For example, policymakers could ask commuters in metropolitan areas to commit to buy a onemonth ticket for public transportation for the following year as soon as a sufficient number of commuters is also willing to keep this commitment. Such a mechanism, which accounts for conditional cooperativeness and impatience, could discourage environmental unfriendly behavior and help sustaining natural resources. 


\section{REFERENCES}

Andreoni, James. "Impure Altruism and Donations to Public Goods: A Theory of WarmGlow Giving?”, Economic Journal, 1990, 100(401), pp. 464-477.

Ashraf, Nava; Karlan, Dean and Wesley, Yin. "Tying Odysseus to the Mast: Evidence from a Commitment Savings Product in the Philippines", Quarterly Journal of Economics, 2006, 121(2), pp. 635-672.

Benz, Matthias and Meier, Stephan. "Do People Behave in Experiments as in Real Life? Evidence from Donations", Experimental Economics, forthcoming.

Benzion, Uri; Rapoport, Amnon and Yagil, Joseph. "Discount Rates Inferred From Decisions: An Experimental Study”, Management Science, 1989, 35, pp. 270-84.

Bolton, Gary E. and Ockenfels, Axel. "ERC: A Theory of Equity, Reciprocity, and Competition”, American Economic Review, 2000, 90(1), pp. 166-193.

Camerer, Colin. "Behavioral Game Theory”, 2003, Princeton University Press: Princeton.

Carpenter, Jeffrey and Seki, Erika. "Do Social Preferences Increase Productivity? Field Experimental Evidence from Fishermen in Toyama Bay", 2005, IZA Working Paper No.1697.

Cavalcanti, Carina. "Recursos Comuns em Unidades de Conservacao de Uso Sustentavel: Estudo de Caso de uma APA", 2003, Unpublished Working Paper.

Cavalcanti, Carina; Schläpfer, Felix and Schmid, Bernard. "Participation and Willingness to Cooperate in CPR Management: A Field Experiment with Fishing Communities in Brazil", 2008, Unpublished Working Paper.

Charness, Gary, and Rabin, Matthew. "Understanding Social Preferences with Simple Tests", Quarterly Journal of Economics, 2002, 117, pp. 817-869.

Croson, Rachel. "Theories of Commitment, Altruism and Reciprocity: Evidence from Linear Public Goods Games", 2008, Working Paper.

Dufwenberg, Martin, and Kirchsteiger, Georg. "A Theory of Sequential Reciprocity“, Games and Economic Behavior, 2004, 47(2), pp. 268-298.

Falk, Armin, and Fischbacher, Urs. "A Theory of Reciprocity“, Games and Economic Behavior, 2006, 54(2), pp. 293-315. 
Farzin, Hossein. "The Effect of the Discount Rate on Depletion of Exhaustible Resources", Journal of Political Economy, 1984, 92(5), pp. 841-851.

Feeny, David; Berkes, Fikret; McCay, Bonnie J. and Acheson, James M. "The tragedy of the commons. Twenty-Two Years Later", Human Ecology, 1990, 18(1), pp. 1-19.

Fehr, Ernst and Gächter, Simon. "Cooperation and Punishment in Public Goods Experiments", American Economic Review, 2000, 90, pp. 980-94.

Fehr, Ernst and Schmidt, Klaus. "A Theory of Fairness, Competition and Cooperation”, Quarterly Journal of Economics, 1999, 114(3), pp. 817-68.

Fischbacher, Urs; Gächter, Simon and Fehr, Ernst. "Are People Conditionally Cooperative? Evidence from a Public Goods Experiment”, Economics Letters, 2001, 71, pp. 397-404.

Frederick, Shane; Loewenstein, George and O`Donoghue, Ted. "Time Discounting and Time Preference: A Critical Review", Journal of Economic Literature, 2002, 40, pp. $351-401$.

Frey, Bruno and Meier, Stephan. "Social Comparison and Pro-Social Behavior: Testing Conditional Cooperation in a Field Experiment”, American Economic Review, 2004, 94(5), pp. 1717-22.

Hardin, Garrett. "The Tragedy of the Commons". Science, 1968, 162 .pp.1246-48.

Kandori, Michihiro. "Social Norms and Community Enforcement", American Economic Review, 1992, 59(1), pp. 63-80.

Karlan, Dean. "Using Experimental Economics to Measure Social Capital and Predict Financial Decisions”, American Economic Review, 2005, 95(5), pp. 1688-99.

Ledyard, John O. "Public Goods: A Survey of Experimental Research" in John H. Kagel and Alvin E. Roth, eds., Handbook of experimental economics. Princeton: Princeton University Press, 1995, pp. 111-94.

Levitt, Steven D. and List, John. "What do Laboratory Experiments Measuring Social Preferences Reveal about the Real World?", Journal of Economic Perspectives, 2007, 21(2), pp. 153-74.

List, John. "The Behavioralist Meets the Market: Measuring Social Preferences and Reputation Effects in Actual Transactions”, Journal of Political Economy, 2006, 114(51), pp. 1-37. 
Meier, Stephan and Sprenger, Charles. "Impatience and Credit Behavior: Evidence from a Field Experiment”, 2007, Federal Reserve Bank of Boston Working Papers 07-3.

Mischel, Walter; Shoda, Yuichi and Rodriguez, Monica L. "Delay of Gratification in Children", Science, 1989, 244, pp. 933-38.

Ostrom, Elinor; Burger, Joanna; Field, Christopher B.; Norgaard, Richard B. and Policansky, David. "Revisting the Commons: Local Lessons, Global Challenges", Science, 1999, 284, pp. 278-82.

Ostrom, Elinor and Nagendra, Harini. "Insights on linking forests, trees, and people from the air, on the ground, and in the laboratory", 2006, Proceedings of the National Academy of Sciences, 103(51), pp. 19221-19223.

Rabin, Matthew. "Incorporating Fairness into Game Theory and Economics", American Economic Review, December 1993, 83(5), pp. 1281-1302.

Shang, Jen and Croson, Rachel. "Field Experiments in Charitable Contributions: The Impact of Social Influence on the Voluntary Provision of Public Goods”, 2008, Working paper.

Sneath, David. "State policy and pasture degradation in Inner Asia", Science, 1998, 281, pp.1147-48.

Sobel, Joel. "Interdependent Preferences and Reciprocity", Journal of Economic Literature, 2005, XLIII, pp. 392-436.

Thaler, Richard H. and Benartzi, Shlomo. "Save More Tomorrow (TM): Using Behavioral Economics to Increase Employee Saving”, Journal of Political Economy, 2004, 112(1), pp. 164-187. 


\section{TABLE 1-EXPLAINING CONTRIBUTIONS IN PGE WITH TIME PREFERENCES}

(OLS)

\begin{tabular}{lcccc}
\hline \hline Dependent Variable & \multicolumn{5}{c}{ Contribution in first period ${ }^{19}$ of PGE } \\
\hline Controls & No & Yes & No & Yes \\
Patience Dummy & 0.0565 & 0.0964 & & \\
(Mineral Water) & $(0.3173)$ & $(0.2787)$ & & 0.1581 \\
Patience Dummy & & & 0.2643 & $(0.2719)$ \\
(Money) & & & $(0.3109)$ & 0.562 \\
P-value & 0.859 & 0.730 & 0.396 & \\
\hline
\end{tabular}

Notes: Observations: 208, robust standard errors in parenthesis. Controls include age, gender, family size, schooling, religiosity, years in profession, session size and village size.

\footnotetext{
${ }^{19}$ The results are similar if we use average contributions in the PGE as dependent variable. For instance, time preferences with regard to mineral water have no predictive power in a model without and with controls $(\mathrm{p}>$ $0.847)$.
} 


\section{TABLE 2-DETERMINANTS OF HOW STRONGLY FISH \& SHRIMP RESOURCES ARE EXPLOITED (OLS, OProbit)}

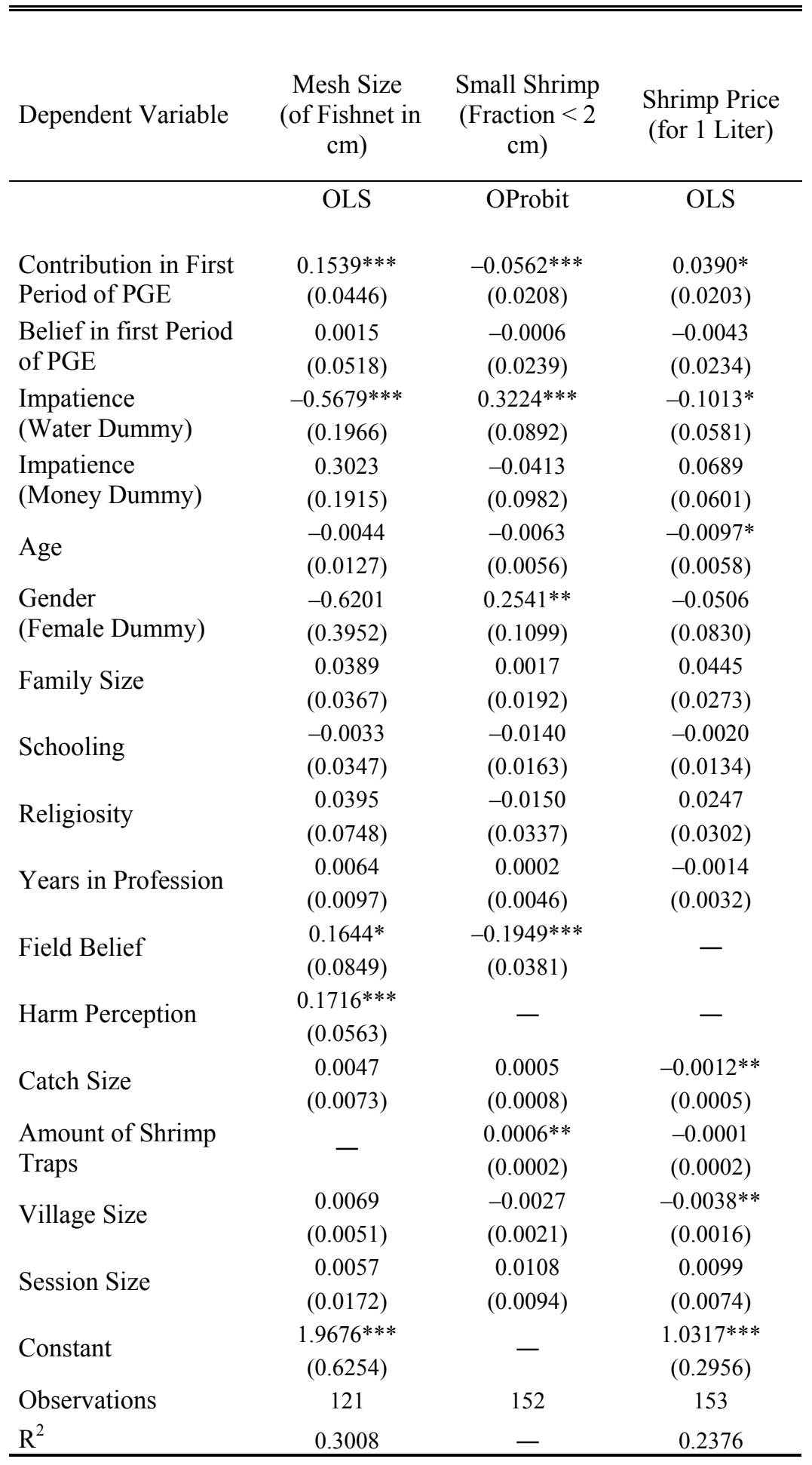

Notes: *** 99-percent significance, ** 95-percent significance; * 90-percent significance. Robust standard errors in parenthesis. For Oprobit: marginal values reported to reach the highest category (catch a high fraction of small shrimp). 